\title{
EL PROBLEMA DEL ORIGEN DEL LENGUAJE DESDE EL PUNTO DE VISTA DE LA LINGÜÍSTICA COGNITIVA
}

\author{
JORGE FERNÁNDEZ JAÉN \\ Universidad de Alicante \\ Jorge.Fernandez@ua.es
}

\section{1. ¿Cuándo apareció el lenguaje? La eterna pregunta}

Probablemente no haya en el marco de las ciencias humanas un asunto más trascendental que el de cuándo y cómo surgió la capacidad lingüística. El lenguaje humano, y esto es algo sabido y compartido por multitud de disciplinas que abarcan desde la filosofía hasta las neurociencias, es sin duda el atributo más distintivo de la especie humana, su más notoria seña de identidad, por lo que dar una respuesta al enigma de su aparición permitiría entender multitud de aspectos decisivos sobre la naturaleza del Homo sapiens. Lejos ya de aquel annus horribilis de 1866 en el que la prestigiosa Société de Linguistique de París prohibió a sus miembros por vía estatutaria la publicación de trabajos que versaran sobre esta cuestión alegando para ello que cualquier hipótesis sobre ese problema no podría pasar nunca de una mera especulación indemostrable $^{1}$ (Iacoboni, 2009: 87), la investigación científica sobre tan fundamental cuestión se halla hoy en día en un momento especialmente productivo. Con todo, sí es de notar que la Lingüística, por paradójico que esto pueda parecer, es la disciplina que más tarde se ha puesto manos a la obra en el empeño de descifrar los entresijos de la glotogonía.

En efecto, hasta hace relativamente poco, los estudios sobre el origen del lenguaje eran desarrollados fundamentalmente por los biólogos y los arqueólogos, mientras que los lingüistas se dedicaban a análisis mucho más inmanentes, de sesgo marcadamente gramatical. Este hecho ilustra perfectamente la actitud que casi siempre ha mantenido la ciencia lingüística acerca de la

1 Prohibición que, por cierto, fue aplaudida por otras instituciones académicas como la British Academy o la Linguistic Society of America, cuyos miembros aprobaron poco después medidas similares (Iacoboni, 2009: 87-88; López García, 2010: 21). 
naturaleza del lenguaje; para muchas escuelas (sobre todo las de inspiración formalista) el lenguaje es un fenómeno autoevidente, casi perfecto, consumado en su propia lógica interna y ajeno a elementos externos. Sin embargo, con la espectacular irrupción de la Gramática Generativa de N. Chomsky en los años 50 y 60 del siglo XX la situación cambia. Chomsky dotará a la Lingüística de una nueva y revolucionaria orientación en la que el lenguaje empezará a considerarse como un atributo natural (y biológico, por tanto) de los seres humanos, codificado en su ADN y regulado por una concreta zona del cerebro especializada en su producción y procesamiento. El lenguaje, por todo ello, se entiende desde esta óptica que ha de ser un instinto biológico. Las consecuencias teóricas de esta hipótesis son notables, sobre todo si se tiene en cuenta que para Chomsky y sus seguidores el origen del lenguaje debió de ser abrupto e inmotivado ${ }^{2}$, producto de una exaptación cerebral que vinculó aleatoriamente las zonas del cerebro adecuadas para que el lenguaje, con su diseño actual, pudiera aparecer ${ }^{3}$.

A pesar de que actualmente contamos con un gran número de trabajos sobre el origen del lenguaje desarrollado en el ámbito de la lingüística generativa, es necesario reconocer que los postulados de Chomsky son, cuando menos, muy parciales a la hora de explicar cómo emergió. Además, numerosas investigaciones, realizadas desde otros campos como la antropología o la psicología evolutiva, indican que las cosas pudieron suceder de un modo muy distinto del que plantea la escuela minimalista del gran investigador norteamericano. Por tanto, existen todavía numerosas preguntas sin responder sobre la cuestión que nos ocupa. Heine y Kuteva (2007: 2-3) plantean, en este sentido, los siguientes interrogantes:

a. ¿Por qué evolucionó el lenguaje y con qué propósito?

b. ¿Dónde y cuándo se desarrolló?

c. ¿Quiénes fueron los creadores del primer lenguaje?

d. ¿Fue su origen monogenético o poligenético? Dicho de otro modo, ¿las lenguas modernas derivan de un lenguaje ancestral o de más de uno?

e. ¿Estaban las formas y estructuras propias del lenguaje primitivo motivadas o eran arbitrarias?

f. ¿Se originó el lenguaje como un sistema vocal o como un sistema gestual?

2 Es decir, que no surgió para cubrir ninguna necesidad previa.

3 No es el propósito de este trabajo explicar los pormenores de los postulados generativistas sobre el origen y propiedades del lenguaje humano. Para un detallado desarrollo de las características de la Gramática Natural de inspiración chomskyana pueden consultarse muchos estudios de reciente publicación, como los de Jenkins (2002), Mendívil Giró (2003, 2009), Lorenzo (2006), Lorenzo y Longa (2003) y Olarrea (2005). 
g. ¿Puede relacionarse la génesis del lenguaje con el comportamiento de los animales?

h. ¿Fue la evolución del lenguaje abrupta o gradual?

i. ¿Qué es más antiguo, el léxico o la gramática?

j. ¿Cómo era la estructura del lenguaje cuando apareció?

k. ¿Cómo ha cambiado el lenguaje desde su origen hasta ahora?

1. ¿Cuánto tiempo tardó en desarrollarse la estructura que podemos encontrar en las lenguas modernas?

m. ¿Cómo se desarrolló la fonología?

n. ¿Cómo aparecieron las propiedades que creemos que son específicas de las lenguas humanas modernas, particularmente la sintaxis y el uso recursivo de las estructuras lingüísticas?

Todas estas preguntas aún no han recibido una respuesta definitiva, por lo que es necesario que la ciencia del lenguaje siga ocupándose de ellas en colaboración con otras disciplinas afines como la biología. En lo que sigue expondremos sucintamente cuáles son las líneas de trabajo que la última gran escuela de la lingüística internacional, la lingüística cognitiva, está desarrollando en la actualidad en el terreno del estudio del origen del lenguaje.

\section{Lingüística cognitiva: un nuevo paradigma}

La historia es conocida. En los años 70 diversos lingüistas como R. Langacker, G. Lakoff o L. Talmy mostraron su descontento con la gramática generativa y propusieron en diversos trabajos inaugurales nuevas ideas acerca de la naturaleza del lenguaje. Poco después aparecieron varios libros en los que cristalizaban esas ideas y adquirían la categoría de modelo teórico plenamente constituido. Así, en 1980 apareció un trabajo ya clásico de Lakoff y Johnson en el que se propone la teoría cognitiva de la metáfora, una de las propuestas más fecundas de la Lingüística de los últimos años. En 1985 Fauconnier presentó la primera versión de la Teoría de los Espacios Mentales (original hipótesis sobre la representación cognitiva del significado) y poco después, en 1987, fueron publicados los trabajos de Lakoff (1987) y de Langacker (1987) que proporcionaron los fundamentos para un análisis cognitivo del significado y de la gramática. Estos trabajos fueron complementados por otros que vendrían poco después, como los de Talmy (1988), Geeraerts (1988, 1997), Taylor (1989), Sweetser (1990), o Langacker (1991), de manera que puede decirse que desde los años noventa la lingüística cognitiva es una disciplina completamente asentada ${ }^{4}$.

4 Buena prueba de ello es la cantidad de asociaciones de lingüística cognitiva que han ido apareciendo por todo el mundo. Desde la página web de la International Cognitive 
La idea fundamental defendida por esta escuela es que el lenguaje humano es un producto cognitivo de representación y verbalización de la realidad relacionado con los demás procesos cognitivos del pensamiento (de los que depende y con los que se integra sin solución de continuidad), tales como la memoria, la percepción sensorial o la capacidad para esquematizar conceptualmente la información. Esta tesis básica se compone de una serie de axiomas, que se pueden resumir como sigue:

a. El lenguaje no debe entenderse como un conjunto finito de reglas matemáticas (al estilo generativista) sino como un sistema maleable e irregular, en el que no hay límites discretos entre las distintas unidades gramaticales. En este sentido, la lingüística cognitiva defiende la prototipicidad de las categorías, es decir la ausencia de equivalencia total de todos los elementos de una categoría concreta. De este modo, este modelo estudia todas las formas lingüísticas, desde las más regulares hasta las más extrañas o periféricas.

b. La sintaxis, la semántica y la pragmática funcionan simultáneamente y son inseparables. En conjunto permiten la existencia de los Modelos Cognitivos Idealizados $\left(\mathrm{MCI}^{6}\right)$ que forman nuestro pensamiento, por lo que no existe una nítida separación entre lo lingüístico y lo enciclopédico o cultural.

c. El lenguaje es, por definición, creativo e imaginativo; el hablante interviene en su diseño aplicando su subjetividad. Por esta razón, las metáforas y

Linguistics Association (http://www.cognitivelinguistics.org) se puede acceder a las distintas webs de muchas de estas asociaciones. En nuestro ámbito cabe mencionar la Asociación Española de Lingüística Cognitiva (http://www.aelco.es), fundada en 1998.

5 Los aspectos que reseñamos se corresponden con la versión clásica de este modelo, aunque es necesario señalar que en estos treinta años de desarrollo de la disciplina los fundamentos teóricos y las aplicaciones descriptivas han aumentado considerablemente. Para una revisión actualizada de los principios de la lingüística cognitiva se pueden consultar los trabajos de Croft y Cruse (2008), Delbecque (2008), Geeraerts (2006), Geeraerts y Cuyckens (2007) o Ibarretxe-Antuñano y Valenzuela (2010), entre otros. También en nuestro país se han publicado muy recientemente dos volúmenes monográficos sobre lingüística cognitiva que cuentan con una nutrida gama de artículos que cubre las nuevas líneas de investigación de ésta, desde los estudios diacrónicos de tipo cognitivo hasta los trabajos de lingüística aplicada a la enseñanza de idiomas: Valenzuela, Rojo y Cifuentes (2007) y Olivares y Llácer (2009).

6 Término propuesto por Lakoff (1987) para denominar a las representaciones mentales con las que conceptualiza el mundo el hablante. Otros autores han propuestos conceptos similares, como el dominio cognitivo (Langacker), marco (Fillmore), espacio mental (Fauconnier), esquemas (Talmy o Rumelhart), escenarios (Schank y Abelson) o modelos mentales (Johnson Laird), aunque todos ellos aluden, aproximadamente, a la misma idea. Para una revisión crítica de estos conceptos véase, por ejemplo, Cifuentes Honrubia (1994: 42-55). 
las metonimias (lejos ya de su definición retórica tradicional), pasan a ser en este modelo los vínculos principales entre realidad y lenguaje.

d. Por todo lo anterior, para la lingüística cognitiva lo primordial para el funcionamiento y desarrollo del lenguaje es el uso pragmático, la comunicación diaria entre los hablantes. De este modo, las necesidades comunicativas, el punto de vista de los participantes, las creencias individuales, los límites biológicos que nos caracterizan como especie, etc., son las fuerzas y barreras que pautan la estructuración lingüística: la necesidad es previa al uso, la función previa a la forma y el significado previo a la abstracción gramatical.

En suma, la lingüística cognitiva es contraria a la tesis generativista de que la gramática (la sintaxis, en realidad) del lenguaje humano sea instintiva y modular, es decir, que sea el producto de una macromutación genética que tuvo lugar en un breve período de tiempo hace unos 140.000 años $^{7}$. La perspectiva cognitiva también rechaza la supuesta autonomía de la sintaxis, o lo que es lo mismo, la desconexión de ésta de otros aspectos de la cognición. En lugar de eso, autores como J. Haiman (1985) o T. Givón (1991) propondrán una visión icónica de la gramática, en la que las estructuras morfosintácticas reproducen parcialmente aspectos relacionados con la captación de la realidad (forma de ver el espacio y comprender el tiempo, por ejemplo) o con el funcionamiento del cerebro ${ }^{8}$.

Lo curioso es que pese a que la lingüística cognitiva posee un más que notable basamento teórico y descriptivo, verificado ya en multitud de lenguas, aún no ha propuesto demasiadas teorías sobre el origen del lenguaje. Da la impresión, incluso, de que este problema tan importante no esté en el programa básico de preocupaciones científicas de esta escuela. Por esta razón, a pesar de que ya contamos con varias décadas de tradición en lingüística cognitiva, su reflexión teórica sobre la glotogonía aún es escasa. En consecuencia, todavía hoy la cuestión del origen del lenguaje sigue pareciendo un asunto propio de los lingüistas generativos ${ }^{9}$. No obstante, en los últimos años

$7 \quad$ Para un detallado análisis de las hipótesis en que se basa esta posible datación véase Olarrea (2005: 16-21).

8 La teoría de la iconicidad lingüística es una de las contestaciones más sólidas a la supuesta autonomía de la sintaxis. Para una reflexión sobre el conflicto teórico autonomíaiconicidad, se pueden consultar los trabajos de Newmeyer (1992) y Croft (1995).

9 Sucede algo parecido con disciplinas como la psicolingüística o la biolingüística, fuertemente vinculadas al modelo chomskyano y casi confundidas con él en no pocas ocasiones. De todas maneras, conviene recordar que el interés de Chomsky por el origen del lenguaje tardó en manifestarse, por razones obvias; si el lenguaje es un producto instintivo, insensible al contexto pragmático y de carácter modular, en principio parece que debe 
diversos lingüistas cognitivos han iniciado interesantes investigaciones en este campo, cuyas principales hipótesis revisaremos en el apartado siguiente.

\section{Un nuevo escenario para el origen del lenguaje}

Tanto la lingüística generativa como la lingüística cognitiva son perspectivas de inspiración psicológica; sin embargo, pese a ese denominador común, ambas difieren en aspectos sustanciales, como ya hemos adelantado. Así, para la escuela de Chomsky el lenguaje es un producto psicológico por el hecho de ser procesado por el cerebro de un modo altamente especializado, mientras que para los autores cognitivos el lenguaje es intrínsecamente psicológico por estar fusionado con los procesos generales de la cognición. Este distinto enfoque comporta estas tres diferencias:

\begin{tabular}{|l|l|}
\hline \multicolumn{1}{|c|}{ Lingüística generativa } & \multicolumn{1}{c|}{ Lingüística cognitiva } \\
\hline - La sintaxis es autónoma. & - La sintaxis es icónica. \\
- La sintaxis es instintiva. & - La sintaxis es funcional. \\
- El uso lingüístico es irrelevante. & - El uso lingüístico es decisivo. \\
\hline
\end{tabular}

Tabla 1. Diferencias básicas entre la lingüística generativa y la lingüística cognitiva.

¿Hay algún modo de compatibilizar estas dos posturas? En principio los desacuerdos entre ambas son irresolubles, puesto que la aceptación de los fundamentos de cualquiera de los dos modelos imposibilita casi por defecto la asunción de hipótesis enunciadas desde el otro. Con todo, es importante insistir en que, discusiones de detalle aparte, hay ideas en ambas perspectivas que pueden ser recuperadas y debidamente aprovechadas ${ }^{10}$. La idea nuclear del generativismo es que el lenguaje es instintivo y la del cognitivismo que el lenguaje es el resultado de la interacción de patrones psicológicos, antropológicos, culturales y sociales; aun así, hay algo que ninguna de las dos perspectivas puede negar: que existen numerosos mecanismos cognitivos en nuestra especie que sí parecen completamente instintivos, tales como la capacidad de comparar diferentes entidades y extraer un patrón común, la capacidad de mentir

ser atemporal e inmutable. Por ello, sólo cuando Chomsky consideró que su teoría había sido lo suficientemente aceptada inició las investigaciones sobre cuándo apareció tan sorprendente y perfecto sistema de comunicación (Kenneally, 2009: 43).

10 Probablemente sea R. Jackendoff $(1999,2002)$ el lingüista que con mayor rigor ha propuesto una unificación entre lingüística generativa y cognitiva en relación con el origen del lenguaje. 
o las habilidades de tipo social. Lo que ocurre es que para los seguidores de Chomsky esos mecanismos son independientes del lenguaje, mientras que los autores cognitivistas aún no han explorado en toda su dimensión su incidencia en el desarrollo de las lenguas naturales ${ }^{11}$. Pues bien, puede que en la interconexión entre los mecanismos innatos y los mecanismos culturales se encuentre un camino sólido para estudiar el origen del lenguaje.

\section{Evolución de la complejidad sintáctica: el regreso al origen del lenguaje}

Numerosos autores contrarios al generativismo han defendido que el lenguaje tuvo que evolucionar de un modo gradual y altamente motivado, siguiendo las pautas de la selección natural de Darwin. Esta idea ha sido aceptada, con los matices necesarios en cada caso, por diversos lingüistas, lo que ha permitido que se hayan hecho ya algunas propuestas interesantes ${ }^{12}$. Lo que este punto de

11 Resultan muy ilustrativas a este respecto estas palabras de Croft y Cruse en la introducción de su libro: "Esta postura [se refieren a los planteamientos básicos de la lingüística cognitiva] se ha interpretado en ocasiones como una recusación de la existencia de una capacidad innata para el lenguaje en el ser humano, pero no tiene por qué ser el caso, puesto que implica tan sólo una recusación de la existencia de una capacidad innata para el lenguaje en la especie humana que tenga un carácter autónomo y un propósito especial. Evidentemente, parece razonable asumir que las capacidades cognitivas humanas de carácter general tengan un componente innato significativo y que algunas de estas propiedades de carácter innato hayan dado lugar a las capacidades humanas de tipo lingüístico, las cuales ninguna otra especie posee aparentemente. Sin embargo, el carácter innato de las capacidades cognitivas no se ha convertido en una preocupación principal para los lingüistas cognitivos, los cuales se han dedicado preferentemente a intentar demostrar el papel que dichas habilidades cognitivas de carácter general desempeñan en el lenguaje" (Croft y Cruse, 2008: 19). También es interesante en este sentido el planteamiento de Taylor y MacLaury (1995) quienes defienden, desde la lingüística cognitivo-funcional, la existencia de restricciones psicológicas esencialmente innatas en la configuración lingüística. Más aún; el propio MacLaury ha llegado a proponer que, quizá, lo único que sucede es que generativistas y cognitivistas están estudiando aspectos distintos del lenguaje humano.

12 Pueden verse sobre ello, entre muchos otros, los trabajos de Pinker (1995), Pinker y Bloom (1990), Johansson (2005) o Kenneally (2009). En nuestro país se han publicado en fecha reciente diversos trabajos que presentan teorías muy interesantes sobre la relación solidaria entre la cognición y el lenguaje. Bernárdez (2008) ofrece interpretaciones muy sugerentes que relacionan el lenguaje con patrones de comportamiento social muy sofisticados (como la cognición sinérgica o supraindividual), mientras que López García (2010) establece un estrecho vínculo entre la capacidad visual, el código genético y la sintaxis. Por otro lado, en Fernández Jaén (2009) se encuentran diversas reflexiones sobre la interacción entre la capacidad de mentir (exclusivamente humana) y el lenguaje, interacción de la cual tal vez hayan surgido productos cognitivos como la ironía o el humor. Finalmente, también pueden consultarse los trabajos recogidos por Givón y Shibatani (2009) que, desde múltiples ángulos teóricos y disciplinarios, plantean análisis sobre cómo pudo desarrollarse gradualmente la gramática. 
vista propone es que el lenguaje, con toda su enorme complejidad actual, quizá no sea más que el resultado de miles de años de evolución gracias a los cuales estructuras simbólicas muy sencillas y motivadas se han ido transformando gradualmente en estructuras paulatinamente más abstractas hasta llegar a un diseño tan complejo que impide ver el camino recorrido. Este marco general de investigación es especialmente importante porque, de demostrarse su tesis, se invalidaría de inmediato el planteamiento chomskyano de que la sintaxis es un producto emergente ajeno a los vaivenes de la evolución natural.

Para Chomsky, la sintaxis no puede derivarse de ninguna necesidad comunicativa previa (la cual forzosamente habría de estar implicada en su desarrollo) sino que debido a su fría lógica interna tuvo que aparecer espontáneamente. En este sentido, la recursividad o capacidad para establecer ilimitadas relaciones de jerarquía estructural entre sintagmas y oraciones a partir de un conjunto finito de reglas transformacionales sería su más notoria seña de identidad. Más aún: la recursividad sigue siendo la propiedad más aparentemente inexplicable de la gramática, por lo que no es extraño que los lingüistas situados en la órbita generativa la invoquen como argumento de autoridad.

Sin embargo, actualmente han sido propuestas desde la perspectiva cognitivista otras interpretaciones que anulan esa concepción de la recursividad como si se tratara de una creación ex nihilo. De entrada, no todas las lenguas tienen recursividad; los pidgins y la lengua Pirahã (hablada en Australia) carecen de ella (Everett, 2005; Heine y Kuteva, 2007: 272). Por otro lado, hay teorías cognitivas que permiten reconstruir cómo se creó la sintaxis y su potencial recursivo, sin acudir en ningún caso a interpretaciones exaptativas. Además, estas teorías se basan en datos lingüísticos de tipo histórico que se pueden someter a interpretaciones estadísticas, por lo que no sólo son plausibles, sino que también son verificables empíricamente.

Los libros de Heine y Kuteva (2007) y Givón (2009) son dos muestras excelentes del rumbo que está tomando la lingüística cognitiva en relación con el origen del lenguaje ${ }^{13}$. Estos dos trabajos, elaborados por tres de los más conspicuos representantes del modelo cognitivo-funcional, muestran de un modo convincente que la gramática puede que no sea más que un diseño complejo creado gracias al efecto de la evolución comunicativa y a la interrelación de múltiples procesos psicológicos. Además, en ambos libros se ejemplifica cada fenómeno analizado con oraciones de numerosas lenguas.

13 Recientemente, Elvira (2009) ha desarrollado un interesante estado de la cuestión sobre las teorías del origen del lenguaje y su relación con la evolución lingüística, centrándose muy especialmente en la sintaxis histórica del español. 
Heine y Kuteva (2007) aplican en su trabajo la teoría de la gramaticalización al origen del lenguaje. Como es sabido, la teoría cognitiva de la gramaticalización se encarga de estudiar los procesos históricos por los que las unidades léxicas libres y plenas semánticamente se transforman con el tiempo en estructuras más abstractas (como adverbios, marcadores discursivos o morfemas) y las unidades gramaticales se vuelven todavía más gramaticales. Lo interesante es que, según han notado muchos autores, los pasos diacrónicos que conducen de lo léxico a lo gramatical son sorprendentemente regulares, como si hubiera guiones totalmente programados a través de los cuales las palabras se convierten en elementos puramente funcionales.

El hecho de que los principios de la gramaticalización sean generales y, normalmente, unidireccionales (es decir, que una vez iniciada una cadena de gramaticalización ésta es irreversible) ha hecho pensar que la evolución gramatical de las lenguas es más estable y predecible de lo que siempre se había creído. Tanto es así que, aceptando una conocida metáfora de Sweetser (1990: 10) podría decirse que una determinada lengua en un momento sincrónico es como una partida de ajedrez a medias; aunque no sepamos cómo se ha llegado a ese resultado podremos suponerlo si conocemos las reglas del juego, del mismo modo que podremos imaginar cómo va a seguir evolucionando en el futuro la partida. De este modo la teoría de la gramaticalización ofrece pautas generales con las que reconstruir la evolución morfosintáctica de las lenguas.

Pues bien, Heine y Kuteva (2007) han aplicado sistemáticamente la teoría de la gramaticalización al origen de la gramática (y, consecuentemente, de la recursividad) siguiendo esta hipótesis: si los cambios por gramaticalización son unidireccionales, ¿podemos desandar el camino y llegar al punto de partida original? Tras analizar procesos de cambio morfosintáctico de unas 500 lenguas y tras contrastar los datos con diversos principios cognitivos, Heine y Kuteva proponen que la gramática se desarrolló siguiendo un patrón compuesto por seis estadios sucesivos, en el que la complejidad formal fue aumentando gradualmente.

En el primer estadio, sólo habría sustantivos. La tesis de que en la gramática primigenia sólo podría haber nombres es perfectamente lógica, teniendo en cuenta que esta clase gramatical es la más básica y la que más procesos de gramaticalización puede desencadenar. En todas las lenguas los sustantivos son capaces de generar adjetivos, adverbios, marcadores discursivos, conjunciones subordinantes y prácticamente cualquier categoría gramatical. Por el contrario, es casi imposible que otra categoría se transforme con el tiempo en 
sustantivo, lo que indica claramente que hay un orden natural de evolución: sustantivos primero, otras categorías después ${ }^{14}$.

Tras el sustantivo es el verbo la categoría gramatical más básica, puesto que expresa nociones elementales como son las acciones, los estados y los procesos, por lo que es lógico que apareciera en un segundo estadio. De hecho, Heine y Kuteva consideran que los verbos quizá se desarrollaron casi al mismo tiempo que los sustantivos. Al igual que éstos, los verbos son una fuente constante de otras categorías por medio de procesos de gramaticalización, y así es frecuente que conduzcan a marcadores discursivos, adverbios, demostrativos o marcas de voz pasiva, tal y como sucede en lenguas como el tagalo, el vietnamita o el chino. Por tanto, en los primeros estadios de la gramática sólo habría sustantivos para nombrar las realidades inmediatas y, poco después, verbos para indicar qué hacen o qué les sucede a esos sustantivos.

Una vez que una gramática básica de sustantivos y verbos estuviera asentada, las necesidades de la comunicación exigirían desarrollar, en un tercer estadio, otras categorías con las que matizar la información expresada por sustantivos y verbos. De este modo, derivados de ellos, aparecieron otras dos categorías, la de los adjetivos, que perfilarían el significado de los sustantivos, y la de los adverbios, para especificar cómo se comportan los verbos. Para Heine y Kuteva estas dos clases de palabras se encuentran en un estadio intermedio porque por un lado sólo pudieron emerger de sustantivos o verbos previos y, por otro, son ellos mismos una fuente muy general de procesos de gramaticalización. Así, los adjetivos se transforman con facilidad en marcadores discursivos, pronombres clíticos y afijos, mientras que de los adverbios suelen derivarse demostrativos (como ocurre en diversa lenguas africanas) elementos subordinantes y marcas aspectuales. Por tanto en este tercer estadio la gramática empezó a articularse en secuencias sintácticas más complejas, con elementos subordinados conceptualmente a otros más prominentes en la secuencia.

En el cuarto estadio la elaboración estructural de la frase aumenta considerablemente. Procedentes de todos los elementos de los estadios anteriores

14 La tesis de que las primeras gramáticas fueron nominales tiene otros datos a su favor. Por ejemplo, las primeras palabras de los niños siempre son sustantivos que hacen referencia a ideas o pensamientos completos (decir pera significa quiero una pera), razón por la cual se entiende en psicolingüística que esas primeras palabras aisladas, denominadas holofrases, permiten transmitir informaciones que sobrepasan lo meramente léxico. Otro dato interesante es que los hablantes afásicos que han perdido parte de su capacidad lingüística por una lesión cerebral, pueden dejar de utilizar adverbios, preposiciones o cualquier otra categoría gramatical (en función del tipo de afasia y de su gravedad) pero tienden a mantener de un modo u otro los sustantivos, que conforman el núcleo mínimo de la comunicación. Para un análisis de las propiedades de los paleolexemas o primeras palabras del lenguaje (fonética, propiedades morfológicas, etc.), véase Fernández Jaén (2010). 
aparecen los demostrativos, las preposiciones, la información aspectual (el grado de perfectividad o imperfectividad de las acciones, estados y procesos expresados por los verbos) y los elementos de negación. Todas estas categorías sirven para expresar información acerca de los sustantivos, verbos y adjetivos con mayor precisión, introduciendo complementos más complejos, referencias deícticas y otros matices expresivos. A pesar de que los elementos que aparecen en este estadio se encuentran ya fuertemente gramaticalizados y tienen muy poco contenido léxico, son capaces de gramaticalizarse aún más, generando otros elementos funcionales ${ }^{15}$. Así, los demostrativos pueden transformarse en pronombres, artículos y conjunciones subordinantes tales como pronombres relativos (como ha sucedido en lenguas como el inglés o el sueco). Las preposiciones, por su parte, se pueden convertir en morfemas de otras palabras y en conjunciones subordinantes, mientras que los elementos aspectuales del verbo pueden generar marcas de temporalidad.

Por todo ello, en un quinto estadio se produjeron los cambios sintácticos más trascendentales. Con el desarrollo de pronombres, artículos y conjunciones surge la subordinación oracional, entendida como la rutinización de estructuras progresivamente más abstractas. Además, con los pronombres se puede utilizar el lenguaje por primera vez para hablar de elementos (personas o cosas) que no están físicamente presentes en el acto comunicativo, lo que se denomina deíxis representacional o fantasmagórica (Cifuentes Honrubia, 1989: 104). Por último, gracias al desarrollo del tiempo verbal (evolucionado a partir del aspecto $^{16}$ ) surge el desplazamiento cognitivo, es decir, el hecho de poder hablar explícitamente del pasado y del futuro y no sólo del presente. Las categorías de este estadio, como se ve, están ya fuertemente gramaticalizadas; aun así, algunos elementos aún pueden gramaticalizarse más.

Finalmente, en el estadio seis la gramática alcanzaría su diseño más sofisticado con el desarrollo de la modalidad deóntica (expresión de la obligatoriedad), la modalidad epistémica (expresión del conocimiento), la diátesis pasiva y la subordinación adverbial. Por ejemplo, como se puede apreciar en vasco, ciertos pronombres se pueden gramaticalizar hasta convertirse en marcas de pasividad.

En definitiva, la propuesta de Heine y Kuteva muestra cómo pudo ir desarrollándose la gramática de una manera progresiva; desde los primeros

15 Los elementos de negación son los únicos de este grupo que no pueden continuar gramaticalizándose.

16 Que el aspecto verbal es previo al tiempo gramatical no sólo se confirma por los datos históricos, sino que también queda de manifiesto por la cantidad de lenguas actuales, como el chino por ejemplo, que no han llegado a gramaticalizar por completo formas temporales pero que sí son muy específicas con la información aspectual (Bernárdez, 2008: 173). 
momentos en que sólo había sustantivos y verbos, se fue pasando a estadios paulatinamente más complejos, y aparecieron poco a poco elementos más funcionales (gramaticalizados siempre a partir de los elementos anteriores) que ajustaron cada vez más la estructuración morfosintáctica. Así, de una sintaxis compuesta únicamente por sustantivos que equivalían a oraciones enteras, se pasó a una sintaxis telegráfica de sustantivos y verbos; después otros elementos aparecieron para matizar semánticamente a los núcleos nominales y verbales y, una vez con sustantivos, verbos, adjetivos y adverbios, la gramaticalización tomó nuevos caminos mucho más abstractos, lo que permitió que se desarrollara la recursividad sintáctica. Con todo, es importante insistir en que esta interpretación de Heine y Kuteva permite imaginar cómo se desarrolló la gramática, pero no predice cuándo aparecieron en la mente del Homo sapiens las necesidades comunicativas que habrían de gramaticalizarse después. Dicho de otro modo: una cosa es determinar de qué categorías proceden los adverbios de negación, por ejemplo, y otra averiguar cuándo tuvieron nuestros antepasados conciencia mental del significado NEGACIÓN, que naturalmente fue antes que la codificación efectiva de ese contenido en forma de adverbio ${ }^{17}$.

Por su parte, Givón (2009) lleva a cabo un interesante análisis de la recursividad oracional. Para este autor la complejidad gramatical está unida a los procesos generales de la evolución humana y, por ello, no es ajena a las pautas de la evolución darwinista. Para Givón el origen de la complejidad sintáctica debe analizarse en tres dominios distintos, a saber:

a. La diacronía: Para entender cómo se desarrolló la complejidad sintáctica se debe analizar la sintaxis histórica de las lenguas actuales.

b. La ontogenia: Los procesos de adquisición lingüística por parte de los niños pueden revelar información básica sobre el desarrollo de la sintaxis en el origen del lenguaje ${ }^{18}$.

c. La filogenia: Las aspectos generales de la evolución humana en términos biológicos resultan indispensables para reconstruir el desarrollo de la sintaxis, puesto que los mecanismos cognitivos y neurológicos (previos al lenguaje y relacionados con él) tuvieron que influir necesariamente en el desarrollo de ésta.

17 Verbos como parar, dejar o ignorar pueden tener significado negativo sin dejar de ser verbos, de manera que es lógico que antes de elementos de negación propiamente dichos hubiera empleos pragmáticos con ese significado, empleos que, con el tiempo, activarían el proceso que conduce a la gramaticalización concreta (Heine y Kuteva, 2007: 306-307). 18 M. Tomasello es uno de los científicos cognitivos que más ha investigado la adquisición lingüística por parte de los niños desde un punto de vista funcional a partir de métodos experimentales. También se ha dedicado a la psicología cognitiva comparada (humanos-chimpancés) y ha propuesto hipótesis muy sólidas sobre cómo se desarrollan el lenguaje y la cultura. Para una aproximación en español a su trabajo véase Tomasello (2007). 
Tendiendo puentes entre estos tres dominios, Givón presenta la sintaxis humana como el resultado de la paulatina elaboración de unas necesidades comunicativas que encontraron en la mente de los hablantes y en su configuración biológica todo lo necesario para desarrollarse; nuestros antepasados construyeron el lenguaje apoyándose en su sistema neurocognitivo, que les permitía usar la memoria para recordar palabras (los elementos, como en la teoría de Heine y Kuteva, más antiguos y primarios), representar mentalmente eventos, y encadenar conceptualmente con el paso del tiempo dichos eventos en estructuras con mayor condensación informativa, como las oraciones subordinadas. Además, la necesidad de transmitir esos contenidos a otros individuos de la especie de un modo rápido hizo que esa capacidad de representación de la realidad se afianzara psicológicamente.

A ello debió de ayudar el entramado neurológico que controla la percepción visual; hoy se sabe que ésta se procesa en el cerebro en dos zonas diferentes (muy próximas a las áreas de Broca y Wernicke, las zonas corticales más importantes para el procesamiento lingüístico), una para la visión de objetos y otra para la comprensión de la movilidad espacial, y quizá aquí se halle el soporte para la configuración básica de las oraciones, puesto que se ha demostrado que ambas zonas se activan mutuamente: el cerebro comprende las palabras (objetos de la realidad) y simultáneamente comprende que éstas se relacionan con acciones verbales (objetos en movimiento) ${ }^{19}$. Por tanto, el desarrollo gradual de la complejidad sintáctica fue posible porque el diseño del cerebro permitió y aun reforzó que así ocurriera.

En suma, para Givón el lenguaje es el producto de la adecuación simultánea de múltiples factores, lo que lo convierte en un diseño altamente complejo. Con todo, por peculiar que pueda parecer la gramática de las lenguas, numerosos

19 López García (2010: 96) también ha reconocido la trascendencia del entramado neuronal responsable de la visión en el origen del lenguaje. Además, la relación entre la visión y el lenguaje se ve favorecida por otro rasgo biológico. Hace unos años, el neurocientífico G. Rizzolatti descubrió, junto con sus colaboradores, unas neuronas en el cerebro humano que se activan tanto cuando una persona hace algo como cuando otra persona ve a alguien hacer esa misma acción. Estas neuronas, bautizadas como neuronas espejo, han revolucionado el mundo científico puesto que desde que se conocen, numerosos comportamientos, como la empatía, la imitación o el aprendizaje, han empezado a entenderse de un modo nuevo; parece que la imitación y la compasión (en su sentido etimológico) no son conductas arbitrarias, sino que vienen en parte impuestas por nuestro diseño neuronal (vemos algo y nos sentimos impelidos a hacer lo mismo). Por supuesto, el estudio del origen del lenguaje también se ha beneficiado de este descubrimiento, puesto que las neuronas espejo explican la rapidez con la que pudo propagarse entre los primeros hablantes. Para un profundo análisis de qué son estas neuronas, cómo funcionan y cómo se relacionan con el lenguaje véase el trabajo de Iacoboni (2009). 
datos procedentes de los tres dominios antes mencionados permiten defender la tesis de que el lenguaje tuvo que crearse siguiendo los mismos principios evolutivos que los demás sistemas complejos de la naturaleza: los de la selección natural. Además, los lingüistas cognitivos hacen suyo en relación al origen del lenguaje el principio teórico del actualismo (utilizado sobre todo en paleontología), que entiende que los fenómenos que hoy pueden observarse tal vez sean semejantes a los fenómenos del pasado; así, los procesos de gramaticalización que se dan en todas las lenguas y que documentamos desde que existe la escritura o las fases de aprendizaje lingüístico de los niños quizá nos muestren, a pequeña escala, los lentos pasos que condujeron al nacimiento del lenguaje ${ }^{20}$.

\section{Algunas conclusiones}

Estas breves notas sobre qué es la lingüística cognitiva, en qué se diferencia de la gramática generativa y cuáles son algunas de las investigaciones actuales sobre el origen del lenguaje desde su ámbito teórico nos permiten extraer algunas conclusiones:

a. El lenguaje humano tuvo que aparecer motivado por el uso comunicativo, y no por un cambio repentino y casual.

b. En la emergencia de las primeras formas lingüísticas, que tuvieron que ser palabras aisladas con un contenido equivalente al de una oración simple, fueron decisivos los engranajes cognitivos previos (compartidos en muchos casos con los primates actuales), los cuales condicionaron sin duda el ulterior diseño del lenguaje. Además, todo apunta a que buena parte de esos principios cognitivos son instintivos.

c. La recursividad de la sintaxis (el elemento más opaco del lenguaje) debió de originarse con el paso del tiempo tomando como punto de arranque las primeras palabras aisladas. En este sentido, la lingüística cognitiva se sitúa junto a la biología darwinista para explicar el desarrollo de la capacidad lingüística, siendo la teoría de la gramaticalización una de las propuestas más sólidas para reconstruir, paso a paso, cómo evolucionó el lenguaje humano desde esas palabras iniciales.

20 Dixon (1997) ha propuesto, a partir de un modelo cognitivo, que las lenguas evolucionan hasta alcanzar altas dosis de complejidad, pero que esa evolución no es lenta sino abrupta; así, siguiendo el principio del equilibrio interrumpido de Eldredge y Gould (1972), Dixon defiende que las lenguas permanecen estables durante largos períodos y que sus transformaciones se producen rápidamente, en intervalos de tiempo relativamente breves. Esta idea no es incompatible con los postulados de la gramaticalización y de la semántica histórica de tipo cognitivo. De hecho, ya existen trabajos (Teixeira, 2004; Grygiel y Kleparski, 2005; Fernández Jaén, 2008) en los que se defiende que las cambios lingüísticos pueden ser más lentos o más repentinos, en función de la cantidad de entropía (o desorden caótico) que tenga la categoría que cambia. 
d. De lo anterior se deriva que no es necesario acudir a los conceptos generativistas de estructura profunda y estructura superficial; toda oración es siempre una conceptualización (en un sentido esencialista) y, por ello, una forma de pensamiento. De este modo, la sintaxis no se volvió compleja porque actuaron reglas gramaticales repentinas, sino que se volvió más elaborada a medida que el pensamiento del Homo sapiens fue adquiriendo más capacidad simbólica y, con ella, un mayor impulso para expresar ideas cada vez más ricas.

e. En última instancia, las pruebas empíricas que demuestren cómo comenzó el lenguaje, han de proceder de dos lugares distintos, según el enfoque que se adopte. Así, la demostración de la hipótesis generativista se debería confirmar desde la biología y la genética, mientras que los postulados cognitivo-funcionales se verifican en el propio sistema lingüístico. Teniendo en cuenta que ya se han encontrado indicios tangibles en este último terreno (procesos de gramaticalización en cientos de lenguas, observaciones sobre el habla infantil, configuración del significado...), todo apunta a que la lingüística cognitiva marcha, en lo referente al origen del lenguaje, por buen camino.

\section{Referencias bibliográficas}

Bernárdez, E. (2008): El lenguaje como cultura. Una crítica del discurso sobre el lenguaje. Madrid, Alianza.

Cifuentes Honrubia, J. L. (1989): Lengua y espacio. Introducción al problema de la deíxis en español. Alicante, Universidad de Alicante.

Cifuentes Honrubia, J. L. (1994): Gramática Cognitiva. Fundamentos críticos. Madrid, Eudema.

Croft, W. (1995): "Autonomy and functionalist linguistics", Language, 71, 3, págs. 490-532.

Croft, W. y D. A. Cruse (2008): Lingüística cognitiva. Madrid, Akal.

Delbecque, N. (2008): "Semántica cognitiva y categorización lingüística". En Rodríguez Espiñeira, $\mathrm{M}^{\mathrm{a}} \mathrm{J}$. y J. Pena Seijas (coords.), Categorización lingüística y limites intercategoriales. Santiago de Compostela, Universidade, págs. 19-56.

Dixon, R. M. W. (1997): The Rise and Fall of Languages. Cambridge, Cambridge University Press.

Eldredge, N. y S. J. Gould (1972): "Punctuated Equilibria: An Alternative to Phyletic Gradualism". En Schopf, T. J. M. (ed.), Models in paleobiology. San Francisco, Freeman, págs. 82-115.

Elvira, J. (2009): Evolución lingüistica y cambio sintáctico. Frankfurt, Peter Lang.

Everett, D. L. (2005): "Cultural constraints on grammar and cognition in Pirahã: another look at the design features of human language", Current Anthropology, 46, (4), págs. 621-646. 
Fauconnier, G. (1985): Mental spaces: Aspects of meaning construction in natural language. Cambridge / New York, Cambridge University Press.

Fernández Jaén, J. (2008): "Semántica histórica y Teoría del Caos", Res Diachronicae, 6, págs. 21-39.

Fernández Jaén, J. (2009): "Ironía y lingüística cognitiva". En Ruiz Gurillo, L. y X. Padilla García (eds.), Dime cómo ironizas y te diré quién eres. Una aproximación pragmática a la ironía. Frankfurt, Peter Lang, págs. 391-422.

Fernández Jaén, J. (2010): "En busca del verbo: gramática histórica y origen del lenguaje". En Encinas Manterola et al (eds.), Ars longa. Diez años de AJIHLE. Buenos Aires, Voces del Sur, págs. 627-642.

Geeraerts, D. (1988): “Where Does Prototypicality Come From?”. En Rudzka-Ostyn, B. (coord.), Topics in Cognitive Linguistics. Amsterdam, John Benjamins, págs. 207-229.

Geeraerts, D. (1997): Diachronic Prototype Semantics. A Contribution to Historical Lexicology. Oxford, Oxford University Press.

Geeraerts, D. (ed.) (2006): Cognitive Linguistics: Basic readings. Berlin, Mouton de Gruyter.

Geeraerts, D. y H. Cuyckens (eds.) (2007): Handbook of Cognitive Linguistics. New York, Oxford University Press.

Givón, T. (1991): "Isomorphism in the grammatical code: cognitive and biological considerations", Studies in Language, 15, 1, págs. 85-114.

Givón, T. (2009): The Genesis of Syntactic Complexity. Diachrony, ontogeny, neuro-cognition, evolution. Amsterdam / Philadelphia, John Benjamins.

Givón, T. y M. Shibatani (eds.) (2009): Syntactic Complexity. Diachrony, acquisition, neuro-cognition, evolution. Ámsterdam / Philadelphia, John Benjamins.

Grygiel, M. y G. Kleparski (2005): "Semantic change and chaos theory", Studia Anglica Resoviensia, 3, págs. 48-58.

Haiman, J. (1985): Natural syntax. Iconicity and erosion. Cambridge, Cambridge University Press.

Heine, B. y T. Kuteva (2007): The Genesis of Grammar. A Reconstruction. Oxford, Oxford University Press.

Iacoboni, M. (2009): Las neuronas espejo. Empatía, neuropolítica, autismo, imitación o de cómo entendemos a los otros. Buenos Aires / Madrid, Katz.

Ibarretxe-Antuñano, I. y J. Valenzuela (2010): "Language as a complex dynamic system: a view from cognitive linguistics". En Bel-Enguix, G. y M. D. JiménezLópez (eds.), Language as a Complex System: Interdisciplinary Approaches. Newcastle, Cambridge Scholars Publishing, págs. 3-38.

Jackendoff, R. (1999): "Possible stages in the evolution of the language capacity", Trends in Cognitive Sciences, 3, págs. 272-279.

Jackendoff, R. (2002): Foundations of Language: Brain, Meaning, Grammar, Evolution. Oxford, Oxford University Press.

Jenkins, L. (2002): Biolingüística. Cambridge, Cambridge University Press.

Johansson, S. (2005): Origins of language-constraints and hypotheses. Amsterdam, John Benjamins. 
Kenneally, C. (2009): La primera palabra. La búsqueda de los orígenes del lenguaje. Madrid, Alianza.

Lakoff, G. (1987): Women, Fire, and Dangerous Things: What Categories Reveal about the Mind. Chicago, University of Chicago Press.

Lakoff, G. y M. Johnson (1980): Metaphors We Live By. Chicago, University of Chicago Press.

Langacker, R. W. (1987): Foundations of cognitive grammar Vol. I. Theoretical Prerequisites. Stanford, Stanford University Press.

Langacker, R. W. (1991): Foundations of cognitive grammar Vol. II. Descriptive Application. Stanford, Stanford University Press.

López García, Á. (2010): El origen del lenguaje. Valencia, Tirant lo Blanch.

Lorenzo González, G. (2006): El vacío sexual, la tautología natural y la promesa minimalista. Ensayos de biolingüística. Madrid, Antonio Machado Libros.

Lorenzo González, G. y V. M. Longa (2003): Homo Loquens. Biología y evolución del lenguaje. Lugo, Tris Tram.

Mendívil Giró, J. L. (2003): Gramática natural. La Gramática Generativa y la Tercera Cultura. Madrid, Antonio Machado Libros.

Mendívil Giró, J. L. (2009): Origen, evolución y diversidad de lenguas. Una aproximación biolingüística. Frankfurt, Peter Lang.

Newmeyer, F. J. (1992): "Iconicity and Generative Grammar", Language, 68, págs. 756-796.

Olarrea, A. (2005): Orígenes del lenguaje y selección natural. Madrid, Equipo Sirius.

Olivares, Ma A. y E. Llácer (eds.) (2009): Nuevas perspectivas en lingüística cognitiva. Quaderns de Filologia. Estudis Lingüístics, 14. València, Universitat de València.

Pinker, S. (1995): El instinto del lenguaje. Madrid, Alianza.

Pinker, S. y P. Bloom (1990): "Natural language and natural selection", Behavioral and Brain Sciences, 13, págs. 707-784.

Sweetser, E. (1990): From etymology to pragmatics. Metaphorical and cultural aspects of semantic structure. Cambridge, Cambridge University Press.

Talmy, L. (1988): "Force dynamics in language and cognition", Cognitive Science, 12, págs. 49-100.

Taylor, J. R. (1989): Linguistic Categorization: Prototypes in Linguistic Theory. Oxford, Clarendon Press.

Taylor, J. R. y R. E. MacLaury (eds.) (1995): Language and the Cognitive Construal of the World. Berlin, Mouton de Gruyter.

Teixeira, J. (2004): "O equilíbrio caótico do significado linguístico", Diacrítica. Ciências da Linguagem, 18/1, págs. 189-207.

Tomasello, M. (2007): Los orígenes culturales de la cognición humana. Buenos Aires, Amorrortu.

Valenzuela, J., A. Rojo y P. Cifuentes (eds.) (2007): Cognitive Linguistics: From Words to Discourse. International Journal of English Studies (Special Issue) Vol. 7.2. Murcia, Universidad de Murcia. 